\title{
Ciência da informação: histórico, delimitação do campo e a sua perspectiva sobre a área da Comunicação
}

\section{Larissa Akabochi de Carvalho}

\begin{abstract}
Mestranda do Programa de Pós-graduação em Ciência da Informação (PPGCI) da Escola de Comunicações e Artes (ECA) da Universidade de São Paulo (USP)
\end{abstract}

Giulia Crippa

Livre-docente em Ciência da Informação pela Faculdade de Filosofia, Ciências e Letras da Universidade de São Paulo

A partir de Saracevic, que aponta a Comunicação como um dos campos interdisciplinares da Ciência da Informação (C.I), este artigo procura estabelecer algumas relações entre essas duas áreas do conhecimento. Primeiramente, reflete sobre o histórico da Ciência da Informação e os três paradigmas (físico, cognitivo e social) que contribuíram para a delimitação do campo. Em seguida, discute a respeito das diferenças entre uma ciência moderna e uma ciência pós-moderna, assinalando que as duas se relacionam com a Ciência da Informação. Por fim, questiona a interdisciplinaridade da C.I e faz algumas considerações sobre os pontos que a separam e a aproximam da Comunicação, enquanto disciplina.

Palavras-chave: Ciência da Informação; Comunicação; Interdisciplinaridade.

\section{Information Science: historical, delimitation of the field and its perspective on the area of Communication}

From Saracevic, which points the Communication as an interdisciplinary field of Information Science (CI), this article seeks to establish some relations between these two areas of knowledge. First, it reflects about the history 
of Information Science and the three paradigms (physical, cognitive and social) that contributed to the delimitation of the field. Then, it discusses about the differences between a modern science and a postmodern science, noting that the two are related to Information Science. Finally, it questions the interdisciplinarity in CI and does some considerations about the points that separate and approach the Information Science from the communication as a discipline.

\section{Keywords: Information Science; Communication; Interdisciplinarity.}

\section{Introdução}

A Ciência da Informação é considerada uma nova ciência (WERSIG, 1993). Mas, embora o termo seja recente, alguns estudos do final do século XIX e início do século XX já eram realizados por Paul Otlet e La Fontaine, no âmbito da documentação. Esta, em sentido amplo, pode ser considerada uma das origens da Ciência da Informação. Para Rayward (1997, p. 19), "na maioria dos casos, nosso termo moderno 'informação' substitui eficientemente o fenômeno abstrato e os processos profissionais e técnicos discutidos por Otlet". Ao longo do tempo, surgiram novos conceitos e novas teorias que contribuíram para a delimitação do campo. Porém, assim como outras ciências, a Ciência da Informação passa por uma crise de identidade.

É constante a afirmação de que ela pertence ao ramo das ciências pós-modernas, devido ao seu caráter interdisciplinar. Mas, ao mesmo tempo, existem vários estudos epistemológicos que buscam e questionam o objeto da área, aproximando a mesma de uma das características principais das ciências modernas. A interdisciplinaridade, por sua vez, é mais falada do que exercida na prática. Como sinalizam Smit, Tálamo e Kobashi (2004), a Ciência da Informação apropria-se de termos de diferentes áreas do conhecimento. Mas, a falta de exportação dos seus próprios termos é uma alerta de que há uma inconsistência na interdisciplinaridade proposta. Para Smit e Tálamo (2007), "a área vem exercendo, de fato, a pluridisciplinaridade e não a interdisciplinaridade", entendendo a pluridisciplinaridade como a "justaposição entre disciplinas diversas" (POMBO, 1994 apud SMIT; TÁLAMO, 2007, p. 36).

A Comunicação, por exemplo, é uma das áreas bastante próximas da Ciência da Informação (C.I). Saracevic (1996) afirma que a Biblioteconomia, a Comunicação, a Ciência Cognitiva e a Ciência da Computação são as quatro principais áreas que se relacionam com a C.I. Este artigo foca nas relações entre a Comunicação (campo) e a Ciência da Informação, pensando as diferenças e afinidades da informação (fenômeno) e a comunicação (processo) (SARACEVIC, 1996). Embora 
essas duas áreas do conhecimento tenham pontos em comum, é importante, também, que se mantenha a autonomia de cada uma.

Assim, primeiramente, o artigo discute o histórico e delimitação do campo da Ciência da Informação, passando pela origem na documentação, a existência dos paradigmas físico, cognitivo e social, os questionamentos a respeito do seu caráter pós-moderno e interdisciplinar e as suas possíveis relações com a área da Comunicação. Não se pretende negar a C.I como uma ciência pós-moderna e/ou que remete à interdisciplinaridade, mas questionar se isso, na prática, acontece.

\section{As origens da ciência da informação}

Barreto (2002, p. 69) diz que Vannevar Bush pode ser considerado o precursor da Ciência da Informação e que seu artigo As we may think, publicado em 1945, "indicou uma mudança de paradigma para a área de informação em ciência e tecnologia". Mas, com isso, ele desconsidera as outras raízes da área, focando a origem da Ciência da Informação na tecnologia. Acontece que só a tecnologia não é suficiente para a apropriação da informação e, para Lund (2009, p. 29), "more focus on document theory is needed to deal with digital".

Any document is a unit containing some representation of information with potential meaning and use (...). Documents and collections have always changed in information value and usefulness over time. People constantly and naturally share ideas with people around them (SCHAMBER, 1996, p. 671).

De acordo com Shapiro (1995 apud RAYWARD, 1997), o termo "Ciência da Informação" foi usado pela primeira vez em 1955. Contudo, Rayward (1997) afirma que a não utilização do termo não pode obscurecer $o$ fato de que os seus principais conceitos, tais como conhecemos hoje, já estavam implícitos quando foram criados no Instituto Internacional de Bibliografia em 1895 e nas décadas seguintes. Desse modo, importantes aspectos das origens da Ciência da Informação estavam contidos ou tornaram-se uma extensão do que entendemos por "documentação". Ainda segundo Rayward (1997, p. 19), "o entendimento de Otlet de documentação ou organização da documentação como sendo um campo de estudo e pesquisa está, de fato, compreendido em nosso termo ciência da informação".

Portanto, considerar o início dessa área do conhecimento na tecnologia, como propõe Barreto (2002), seria negligenciar importantes estudos, na área da documentação, que contribuíram para a delimitação do campo. Para Ortega (2009, p. 30), "the documentary principles are configured as a base part of the groundings of Information Science, and are emblematic of its identify unit".

Capurro (2003), por sua vez, formulou uma tese de que a Ciência da Informação nasceu a partir de três paradigmas: o físico, o cognitivo e o 
social. O paradigma físico postula que há um objeto físico que o emissor transmite ao receptor, desconsiderando o papel ativo do usuário (sujeito cognoscente) no processo de recuperação da informação, bem como em todo processo informativo e comunicativo em geral. Já o paradigma cognitivo, concentra-se no sujeito individual e cognoscente, possuidor de modelos mentais que são transformados durante o processo informacional (CAPURRO, 2003). A informação é vista como aquela que afeta ou muda o estado da mente (SARACEVIC, 1999). Por último, o paradigma social trata a informação não apenas como uma mensagem (paradigma físico) processada a um nível cognitivo (paradigma cognitivo), mas na sua relação com o contexto, a situação, a motivação e a intencionalidade (SARACEVIC, 1999). Só tem sentido falar de um conhecimento como informativo em relação a um pressuposto conhecido e compartilhado com outros, com respeito ao qual a informação pode ter o caráter de ser nova e relevante para um grupo ou para um indivíduo (CAPURRO, 2003, p. 8).

Mas, embora o paradigma social esteja em pauta, ainda existem os três paradigmas. Portanto, podemos pensá-los como ênfases que foram e que são dadas de acordo com o momento. Segundo Vega-Almeida, Fernández-Molina e Linares (2009), os três foram importantes para a Ciência da Informação. O paradigma físico contribuiu para a configuração da área enquanto disciplina, estabelecendo suas teorias e métodos fundamentais; o paradigma cognitivo expressou e refletiu uma mudança social e intelectual ao centrar no sujeito enquanto indivíduo; e o paradigma social ampliou o paradigma cognitivo, enfatizando a historicidade de todos os fenômenos sociais e questionando os elementos subjetivos dos modelos teóricos.

\section{Ciência moderna e ciência pós-moderna}

De acordo com algumas agências de financiamento, como a Coordenação de Aperfeiçoamento de Pessoal de Nível Superior (Capes), e o Conselho Nacional de Desenvolvimento Científico e Tecnológico (CNPq), a Ciência da Informação é classificada como uma ciência social aplicada. Le Coadic (1996, p. 21) afirma o seu caráter social ao dizer que

a ciência da informação, com a preocupação de esclarecer um problema social concreto, o da informação, e voltada para o ser social que procura informação, coloca-se no campo das ciências sociais (das ciências do homem e da sociedade), que são o meio principal de acesso a uma compreensão do social e do cultural.

Borko (1968 apud SARACEVIC, 1996, p. 45-46), por sua vez, aponta que "ela tem tanto um componente de ciência pura, através da pesquisa dos fundamentos, sem atentar para sua aplicação, quanto um componente de ciência aplicada, ao desenvolver produtos e serviços". Para Smit e Tálamo (2007), o entendimento de um caráter aplicado 
demanda discussões sobre as diferenças entre uma ciência moderna e uma ciência pós-moderna.

A ciência moderna tende a segregar a organização do saber, delimitando rigorosamente as fronteiras entre as disciplinas. Neste sentido, o conhecimento avança de acordo com a especialização. Contudo, Santos (1987, p. 46) acredita que isso faz do cientista um ignorante especializado e acarreta efeitos negativos, principalmente no domínio das ciências aplicadas.

A ciência moderna produz conhecimentos e desconhecimentos. Se faz do cientista um ignorante especializado faz do cidadão comum um ignorante generalizado. Ao contrário, a ciência pós-moderna sabe que nenhuma forma de conhecimento é, em si mesma, racional; só a configuração de todas elas é racional. Tenta, pois, dialogar com outras formas de conhecimento deixando-se penetrar por elas (SANTOS, 1987, p. 55).

Por outro lado, a ciência moderna acredita na ruptura do modelo científico com o senso comum e que a ciência deve elaborar procedimentos metodológicos objetivos a fim de gerar um conhecimento legítimo (SMIT; TÁLAMO, 2007). A ciência pós-moderna, por sua vez, reconhece no senso comum algumas virtualidades que podem enriquecer a nossa relação com o mundo (SANTOS, 1987, p. 55 e 56).

Nesse sentido, o diálogo entre ciência e senso comum pode ser produtivo, como afirma Santos (1987), na medida em que ocorra uma inversão na ruptura epistemológica. Ao invés do salto ser do conhecimento do senso comum para o conhecimento científico, como postula a ciência moderna, ele deve ser do conhecimento científico para o senso comum, visto que o conhecimento científico pós-moderno apenas se realiza quando convertido para o senso comum.

Ao contrário da ciência clássica, a ciência pós-moderna "reconhece que nenhuma forma de conhecimento é necessariamente superior às demais" (SMIT; TÁLAMO, 2007, p. 34). Desse modo, Wersig (1993) afirma que a Ciência da Informação não pode ser vista como uma disciplina clássica, mas como um novo tipo de ciência ou ciência pósmoderna. Este novo tipo de ciência não se dirige para um entendimento completo de como nosso mundo funciona, mas pela necessidade de entender, resolver ou lidar com problemas.

Contudo, ao mesmo tempo em que a Ciência da Informação se assume como uma ciência pós-moderna, permanece a busca de qual seria o seu objeto, remetendo a uma das características básicas das ciências modernas (SMIT; TÁLAMO, 2007). Isso constitui um problema na medida em que revela uma incongruência na delimitação da área.

Se a ciência moderna baseia-se metodologicamente no princípio cartesiano das ideias simples e claras, uma ciência pós-moderna, cuja característica fundamental é a de adotar 
como paradigma o princípio da complexidade, deve igualmente buscar novos caminhos para construir-se enquanto saber (KOBASHI; TÁLAMO, 2003, p. 17).

Segundo Wersig (1993), a falta de um método e objeto únicos, impede a Ciência da Informação de alcançar o status de ciência clássica. Contudo, ela não tem um objeto único porque todos os objetos possíveis já foram apropriados por outras disciplinas. Assim, ela não pode desenvolver um método específico devido à obscuridade do tema. Mas, de acordo com Santos (1987, p. 48), é aí que reside uma característica do conhecimento pós-moderno. Este se constitui a partir de uma pluralidade de métodos, a qual só é possível mediante uma transgressão metodológica. O estilo da ciência pós-moderna seria "uma configuração de estilos construída segundo o critério e a imaginação pessoal do cientista" (SANTOS, 1987, p. 49).

Voltando à questão do objeto da Ciência da Informação, ela ainda é bastante discutida, e dizer que o objeto da área é a informação causa mais dúvidas e problemas epistemológicos do que soluções. Portanto, um dos caminhos encontrados foi a afirmação do caráter interdisciplinar da Ciência da Informação, visto que isso "confere-lhe estatuto científico e funcionalidade" (SMIT; TÁLAMO, 2007, p. 35). Para Araújo (2003, p. 26), "no caso da ciência da informação, a característica mais importante que marca sua postura como uma ciência pós-moderna é a aceitação de sua natureza interdisciplinar em essência".

\section{A área da Comunicação pela perspectiva da Ciência da Informação: possíveis relações interdisciplinares}

A interdisciplinaridade pode ser confundida com a mera incorporação de conceitos, teorias e métodos de uma disciplina para a outra (GOMES, 2001). Mas, ela apenas se concretiza se houver um diálogo, de fato, entre as disciplinas (SILVA; FUJITA; DAL' EVEDOVE, 2009). Como foi dito anteriormente, afirma-se 0 caráter interdisciplinar da Ciência da Informação e, com isso, pouco se discute a respeito do assunto.

Smit e Tálamo (2007) dizem que uma característica das ciências aplicadas é, justamente, adotar teorias de outras áreas. Porém, considerando que a interdisciplinaridade, para Pombo (1994, p. 13 apud SMIT; TÁLAMO, 2007, p. 36), reflete a combinação entre duas ou mais disciplinas a fim de compreender um objeto, por pontos de vista diferentes, e chegar à elaboração de um objeto comum, as autoras questionam o tipo de interdisciplinaridade que tem sido colocado em prática pela Ciência da Informação.

O fenômeno da importação terminológica, muito frequente em Ciência da Informação, aponta para uma área que mantém interfaces bastante próximas com uma diversidade de outras áreas do conhecimento, mas também permite refletir sobre as razões da ausência de 
'exportações' de termos da Ciência da Informação para as outras áreas [...]. A alta proporção de 'noções emprestadas' é reveladora, a nosso ver, de uma interdisciplinaridade formal, que não reflete uma interdisciplinaridade real mas um "empréstimo" de termos de outras áreas, sem que haja uma adaptação, ou customização, dos conceitos aos propósitos da área. (SMIT; TÁLAMO; KOBASHI, 2004, p. 9).

Pinheiro (2002, p. 2) corrobora as autoras e diz que, na Ciência da Informação, "o terreno interdisciplinar é muito vasto e inicialmente não foram explicitadas essas relações, além de não haver, ainda, consistência teórica, o que demanda mais estudos epistemológicos nessa linha". Mas, algumas definições já foram feitas, como a de Saracevic (1996). Ele diz que a Ciência da Informação possui fortes relações interdisciplinares com as seguintes áreas: Biblioteconomia, Ciência da Computação, Ciência Cognitiva e Comunicação. Este artigo foca nas afinidades existentes com a última. "De forma fundamental, as relações entre o fenômeno e o processo - informação e comunicação - definem as relações entre CI e comunicação (campo)" (SARACEVIC, 1996, p. 53).

Com efeito, a Ciência da Informação preocupa-se com a pesquisa científica e a prática profissional relativas à comunicação, necessidades e uso da informação em contextos sociais, institucionais e individuais. Informação e comunicação são as palavras-chave de sua proposição (KOBASHI, TÁLAMO, 2003, p. 13).

De acordo com Shannon (1948 apud CAPURRO; HJORLAND, 2007), a informação é algo que flui entre um emissor e um receptor. Mas, esta definição é quantitativa e, como observa Underwood (2001 apud CAPURRO; HJORLAND, 2007), é uma teoria de transmissão de sinal ou mensagem, não uma transmissão de informação. Para Gomes (2001), a informação (conhecimento comunicado) que chega ao receptor não é absorvida automaticamente pelo mesmo.

Apesar disso, Capurro e Hjorland (2007) observam que Shannon conservou um aspecto básico do moderno conceito de informação, o de comunicação de conhecimento, ou seja, seleção. Para Luhmann (1987 apud CAPURRO; HJORLAND, 2007), existe uma oferta de significados a partir dos quais uma escolha deve ser feita. Comunicação é a união entre oferta de significados, informação e compreensão. De acordo com essa teoria, não há transmissão de informação entre emissor e receptor. A informação não é idêntica para o emissor e o receptor. Ela deve ser construída pelo processo de comunicação.

Portanto, as relações entre informação (fenômeno) e comunicação (processo) são bastante estreitas, o que aproxima a Ciência da Informação da Comunicação (campo). Todavia, essa aproximação não 
pode gerar confusões entre as duas áreas do conhecimento. Algumas diferenças devem ser explicitadas. Para Dias (2002), a Ciência da Informação trabalha com a informação registrada e a busca nos sistemas de informação e de recuperação da informação (SIRIs) não deve ser confundida com a busca que se faz fora desses sistemas (informação nãoregistrada), que é objeto da Comunicação (campo).

Como são várias as áreas do conhecimento que lidam com a informação, Barreto (2002 apud DIAS, 2002) acredita que é necessário identificar o diferencial da Ciência da Informação. Para ele, a organização da informação pode ser considerada a forma específica que a CI trata e lida com a informação, distinguindo-a da Comunicação e das outras disciplinas.

Mas, embora seja importante que cada área tenha a sua própria identidade, pesquisadores que trabalham tanto em CI como em Comunicação entendem que o foco unilateral em informação ou comunicação enfraquece a pesquisa de ambos. As duas áreas compartilham o interesse pela comunicação humana e há uma compreensão de que "a informação como fenômeno e a comunicação como processo devem ser estudadas em conjunto" (SARACEVIC, 1996, p. $54)$.

\section{Considerações finais}

Como já foi dito, a proposta deste artigo não foi negar que a Ciência da Informação é uma ciência pós-moderna e interdisciplinar, mas questionar essas afirmações, no sentido de que elas não se mostram sólidas na área. Afinal, ao mesmo tempo em que a C.I possui características de uma ciência pós-moderna, devido ao seu diálogo com outras disciplinas, ela também possui características de uma ciência moderna pela procura que muitos pesquisadores ainda fazem de seu objeto.

Quanto à interdisciplinaridade na área, ela deveria ser mais concreta. A simples apropriação de termos, conceitos e métodos de outras áreas para a Ciência da Informação não é sinônimo de que realmente acontece uma relação dialógica. Para isso, as disciplinas envolvidas devem ter a sua própria identidade a fim de, por diferentes pontos de vista, chegarem à compreensão de um objeto comum.

Em meio às possíveis relações interdisciplinares que podem ser estabelecidas com a Ciência da Informação e outras áreas do conhecimento, este artigo focou na Comunicação. Acredita-se que esta parceria traz benefícios para ambas, na medida em que a interdisciplinaridade é colocada em prática. Nesse sentido, são importantes os estudos sobre o histórico da C.I e a sua delimitação como ciência pós-moderna e interdisciplinar, visto que isso é mais afirmado do que fonte de discussão. Porém, ao lado dessas discussões, seria relevante também que a área se dedicasse mais à análise de problemas e proposta de soluções, como sugere Wersig (1993). Compartilha-se com as ideias de 
Smit e Tálamo (2007, p. 44), quando dizem que "este esforço certamente reverteria numa maior visibilidade - e reconhecimento - social do campo".

\section{Referências}

ARAÚJO, C. A. A ciência da informação como ciência social. Ciência da Informação, v. 32, n. 3, p. 21-27, set./dez. 2003. Disponível em: <http://www.scielo.br/pdf/ci/v32n3/19020.pdf>. Acesso em: 21 nov. 2012.

BARRETO, A. de A. A condição da informação. Revista São Paulo em Perspectiva, v. 16, n. 3, p. 67-74, 2002. Disponível em: <http://www.seade.gov.br/produtos/spp/v16n03/v16n03_09.pdf>.

Acesso em: 21 nov. 2012 apud DIAS, E. W. Ensino e pesquisa em ciência da informação. DataGramaZero, v. 3, n. 5, out. 2002. Disponível em: <http://www.dgz.org.br/out02/Art_02.htm>. Acesso em: 21 nov. 2012.

BORKO, $\mathrm{H}$. Information science: what is it? American Documentation, v. 19, n. 1, p. 3-5, 1968 apud SARACEVIC, T. Ciência da Informação: origem, evolução e relações. Perspectivas em Ciência da Informação, Belo Horizonte, v. 1, n. 1, p. 41-62, jan./jul. 1996. Disponível em: <http://portaldeperiodicos.eci.ufmg.br/index.php/pci/article/view/235/22 >. Acesso em: 21 nov. 2012.

CAPURRO, R. Epistemologia e ciência da informação. In: ENCONTRO NACIONAL DE PESQUISA EM CIÊNCIA DA INFORMAÇÃO, 5., 2003, Belo Horizonte. Anais... Minas Gerais: UFMG, 2003.

CAPURRO, R., HJORLAND, B. O conceito de informação. Perspectivas em Ciência da Informação, v. 12, n. 1, p. 148-207, 2007. Disponível em: <http://portaldeperiodicos.eci.ufmg.br/index.php/pci/article/view/54/47>. Acesso em 21 nov. 2012.

DIAS, E. W. Ensino e pesquisa em ciência da informação. DataGramaZero, v. 3, n. 5, out. 2002. Disponível em: <http://www.dgz.org.br/out02/Art_02.htm>. Acesso em: 21 nov. 2012.

GOMES, H. F. Interdisciplinaridade e ciência da Informação: de características a critério delineador de seu núcleo principal. DataGramaZero, v. 2, n. 4, ago. 2001. Disponível em: <http://www.dgz.org.br/ago01/Art_04.htm>. Acesso em: 21 nov. 2012.

KOBASHI, N. Y.; TÁLAMO, M. F. G. Informação: fenômeno e objeto de estudo da sociedade contemporânea. Transinformação, v. 15, edição especial, p. 7-21, set./dez. 2003. Disponível em: <http://wersig.objectis.net/artigos/30\%20artigo.pdf>. Acesso em: 21 nov. 2012.

LE COADIC, Y. A ciência da informação. Brasília: Briquet de Lemos, 1996.

LUHMANN, N. Soziale systeme: grundriss einer allgemeinen theorie. Frankfurt/Main: Suhrkamp, 1987 apud CAPURRO, R., HJORLAND, B. O conceito de informação. Perspectivas em Ciência da Informação, v. 12, n. 
1, p. 148-207, 2007. Disponível em: <http://portaldeperiodicos.eci.ufmg.br/index.php/pci/article/view/54/47>. Acesso em 21 nov. 2012.

LUND, N. W. Document theory. Annual Review of Information Science and Technology, v. 43, n. 1, p. 1-55, 2009.

ORTEGA, C. D. Documentation as one of the origins of the information science and a fertile basis for its grounding. Brazilian Journal of Information Science, v. 3, n. 1, p. 3-34, 2009. Disponível em: $<$ http://www2.marilia.unesp.br/revistas/index.php/bjis/article/viewFile/48 /275>. Acesso em 21 nov. 2012.

PINHEIRO, L. V. R. Gênese da Ciência da Informação ou sinais anunciadores da nova área. In: AQUINO, M. (Org.). O campo da Ciência da Informação: gênese, conexões e especificidades. João Pessoa: Editora da UFPB, 2002. p. 61-86.

POMBO, O. Interdisciplinaridade: conceito, problemas e perspectivas. In: LEVY, T., GUIMARÃES, H.; POMBO, O. A interdisciplinaridade: reflexão e experiência. 2. ed. rev. e aum. Lisboa: Texto, 1994. p. 8-14 apud SMIT, J. W.; TÁLAMO, M. F. G. Ciência da Informação: um ciência moderna ou pósmoderna? In: LARA, M. L. G. et al. Informação e Contemporaneidade: perspectivas. Recife: Néctar, 2007, p. 27-46. Disponível em: <http://www.pos.eca.usp.br/sites/default/files/file/cienciaInformacao/info rmacaoContemporaniedade.pdf>. Acesso em: 21 nov. 2012.

RAYWARD, W. B. The origins of information science and the International Institute of Bibliography/International federation for Information and Documentation (FID). Journal of the American Society for Information Science, v. 48, n. 4, p. 289-300, 1997.

SANTOS, B. S. Um discurso sobre as ciências. Porto: Afrontamento, 1987.

SARACEVIC, T. Information Science. JASIS - Journal of the American Society for Information Science, v. 50, n. 12, p. 1051-1063, 1999.

SARACEVIC, T. Ciência da Informação: origem, evolução e relações. Perspectivas

em Ciência da Informação, Belo Horizonte, v. 1, n. 1, p. 41-62, jan./jul. 1996.

<http://portaldeperiodicos.eci.ufmg.br/index.php/pci/article/view/235/22

>. Acesso em: 21 nov. 2012.

SCHAMBER, L. What is a document? Rethinking the concept in uneasy times. Journal of the American Society for Information Science, v. 47, n. 9, p. 669-671, 1996.

SHANNON, C. A mathematical theory of communication. Bell System Technical Journal, v. 27, p. 379-423, 1948 apud CAPURRO, R., HJORLAND, B. O conceito de informação. Perspectivas em Ciência da Informação, v. 12, n. 1, p. 148-207, 2007. Disponível em: 
<http://portaldeperiodicos.eci.ufmg.br/index.php/pci/article/view/54/47>. Acesso em 21 nov. 2012.

SHAPIRO, F. R. Coinage of the term information science. Journal of the American Society for Information Science, v. 46, p. 384-385, 1995 apud RAYWARD, W. B. The origins of information science and the International Institute of Bibliography/International federation for Information and Documentation (FID). Journal of the American Society for Information Science, v. 48, n. 4, p. 289-300, 1997.

SILVA, I. O; FUJITA, M. S. L.; DAL' EVEDOVE, P. R. A relação entre arquivística e ciência da informação na sociedade pós-moderna. In: ENCUENTROS INTERNACIONALES SOBRE SISTEMAS DE INFORMACIÓN Y DOCUMENTACIÓN, 14., 2009, Zaragoza. Anais... España: Ibersid, 2009.

SMIT, J. W.; TÁLAMO, M. F. G. Ciência da Informação: um ciência moderna ou pós-moderna? In: LARA, M. L. G. et al. Informação e Contemporaneidade: perspectivas. Recife: Néctar, 2007, p. 27-46. Disponível em: <http://www.pos.eca.usp.br/sites/default/files/file/cienciaInformacao/info rmacaoContemporaniedade.pdf>. Acesso em: 21 nov. 2012.

SMIT, J. W.; TÁLAMO, M. F. G; KOBASHI, N. Y. A determinação do campo científico da ciência da informação: uma abordagem terminológica. DataGramaZero, v. 5, n. 1, fev. 2004. Disponível em: <http://www.dgz.org.br/fev04/Art_03.htm>. Acesso em: 21 nov. 2012.

VEGA-ALMEIDA， R. L; FERNANDEZ-MOLINA， J. C.; LINARES， R. Coordenadas paradigmáticas, históricas y epistemológicas de la Ciência de la Información: uma sistematización. Information Research, v. 14, n. 2, 2009. Disponível em: <http://informationr.net/ir/14-2/paper399.html>. Acesso em: 21 nov. 2012.

WERSIG, G. Information Science: the study of postmodern knowledge usage. Information Processing \& Management, v. 29, n. 2, p. 229-239, 1993. 